\title{
Landsat and Sentinel-2 images as a tool for the effective estimation of winter and spring cultivar growth and yield prediction in the Czech Republic**
}

\author{
Zdeněk Jelinek ${ }^{1}{ }^{*}$, Jitka Kumhálová ${ }^{1}$, Jan Chyba ${ }^{2}$, Marie Wohlmuthová ${ }^{3}$, Mikuláš Madaras ${ }^{4}$, \\ and František Kumhála ${ }^{4}$ (1) \\ ${ }^{1}$ Department of Machinery Utilization, Faculty of Engineering, ${ }^{2}$ Department of Agricultural Machines, Faculty of Engineering, \\ ${ }^{3}$ Department of Mathematics, Faculty of Engineering, \\ Czech University of Life Sciences, Kamýcká 129, 16521 Prague 6 - Suchdol, Czech Republic \\ ${ }^{4}$ Division of Crop Management Systems, Crop Research Institute, Drnovská 507, 16100 Prague 6 - Ruzyně, Czech Republic
}

Received June 6, 2020; accepted August 14, 2020

\begin{abstract}
The influence of climate and topography on crop condition and yield estimates is most effectively monitored by non-invasive satellite imagery. This paper evaluates the efficiency of free-access Sentinel 2 and Landsat 5, 7 and 8 satellite images scanned by different sensors on wheat growth and yield prediction. Five winter and spring wheat cultivars were grown between 2005 and 2017 in a relatively small 11.5 ha field with a $6 \%$ slope. The normalized difference vegetation index was derived from the satellite images acquired for later growth phases of the wheat crops (Biologische Bundesanstalt, Bundessorenamt and Chemical industry $55-70$ ) and then compared with the topography wetness index, crop yields and yield frequency maps. The results showed a better correlation of data obtained over one day $\left(\mathrm{R}^{2}=0.876\right)$ than data with a one-day delay $\left(\mathrm{R}^{2}=0.689\right)$ using the Sentinel 2 B8 band instead of the B8A band for the near-infrared part of electromagnetic spectrum in the normalized difference vegetation index calculation.
\end{abstract}

Keywords: satellite sensors, agriculture, satellite imagery, wheat varieties

\section{INTRODUCTION}

Optical satellite images are widely used to evaluate long-term changes in landscape cover and vegetation (Jamali et al., 2015; Julien et al., 2011). They have proven to be effective in studying spatio-temporal changes in

*Corresponding author e-mail: jelinekzdenek@tf.czu.cz

**This work was supported by Internal Grant Agency of the Faculty of Engineering, CZU Prague, internal grant number $31180 / 1312 / 3118$. The support from project MZE-RO418 is also acknowledged (2018-2022). crop development and crop yield prediction (Shanahan et al., 2001; Kumhálová et al., 2014). Information obtained from optical satellite images provides agronomists with a better understanding of crop growth in relation to rainfall and site-specific agro-ecological conditions. This knowledge is crucial for crop stress detection, especially in years of decreased precipitation and uneven water distribution (Domínguez et al., 2017).

A new generation of satellites equipped with improved sensors can help agronomists to maximize and sustain crop production during climate change. The information they deliver contributes to a better understanding of crop cultivar response to water deficit.

The actual information concerning crop growth and cultivar adaptation to weather and site conditions during the vegetation season is provided by freely available data from several satellites: Landsat 5 (L5) with a Thematic Mapper (TM) sensor, Landsat 7 (L7) with an Enhanced Thematic Mapper Plus (ETM+) instrument (Domínguez et al., 2015, 2017), Landsat 8 (L8) with an Operational Land Imager (OLI) and Sentinel 2 (S2) with a Multi-Spectral Instrument (MSI) (Clevers et al., 2017; Flynn et al., 2020). However, in order to obtain useful information about crop spectral reflectance, advanced knowledge is required for appropriate data processing. Traditional satellite systems have been used for agricultural purposes (Kumhálová and Matějková,

(C) 2020 Institute of Agrophysics, Polish Academy of Sciences 
2017) and they were helpful in demonstrating trends and discrete changes in crop development time series (Goméz et al., 2016), even though other studies based on Landsat satellite images showed that a $30 \mathrm{~m}$ spatial resolution is too imprecise in practice (Scudiero et al., 2016).

The European Space Agency's (ESA) S2 satellite with 10 to $60 \mathrm{~m}$ spatial resolution for individual spectral bands provides 5 days of temporal resolution at the equator (Copernicus Open Access Hub, 2018), which enables the detection of important plant biophysical and biochemical variables such as leaf water content and crop health (Chemura et al., 2018).

The oldest and most widely used vegetation index is the normalized difference vegetation index (NDVI). This index is based on crop canopy absorption differences in the red and near-infrared electromagnetic spectra (Julien et al., 2011). NDVI can be used to successfully monitor the seasonal variability of plant phenology caused by changes in temperature and various rainfall regimes (Heumann et al., 2007), it is therefore suitable for detecting in-field variability (Viña et al., 2011).

Crops reach satisfactory yields only with a sufficient water supply (Schmidt and Persson, 2003). On-field water redistribution is a function of both soil properties and topography. The literature includes records of several methods of describing and modelling these redistribution processes. The most useful models are the D8 algorithm, the MFD8 algorithm and the topography wetness index (TWI), which describe on-field water redistribution and moisture potential at different levels (Schmidt and Persson, 2003; Sørensen et al., 2006; Kumhálová et al., 2014).

The foregoing research showed that the interpretation of crop maps based on spectral indices is very difficult without any additional knowledge of soil properties, topography, weather and other environmental factors influencing crop yield variability (Doerge, 1999; Long and McCallum, 2014; Jin et al., 2017). Despite these limitations, yield potential can be defined and modelled to provide a better understanding of crop growth and final yield. For example, Evans (1993) defined yield potential as the yield resulting from growing crops in environments with an unlimited supply of water and nutrients, and where pests, weeds and biotic disease factors are effectively controlled. Andarzian et al. (2008) showed that the yield potential of a given crop cultivar in a specific growth environment is determined by the amount of incident solar radiation, temperature and plant density.

Numerous studies have also been published in the past two decades which have established crop yield gaps as the difference between crop yield potential and actual farm yields. Understanding the causes of yield gaps is necessary for increasing crop production at both local and global scales, especially when climate change effects on future crop yields and land-use change are considered (Grassini et al., 2015; Guilpart et al., 2017; Mueller et al., 2013). For visualization and an improved interpretation of year-to-year crop yield variability, Maphanyane et al. (2018) developed the concept of a normalized yield frequency map, which uses the conversion of absolute yields to relative yields.

Wheat (Triticum spp.) is one of the most important global agricultural crops. In order to understand wheat growth status at each specific developmental stage, farmers use various advanced tools to optimize wheat yield and grain quality (Wu et al., 2016). In this regard, Wheeler et al. (1996) determined that environmental conditions, especially mean temperature, have a significant impact on wheat growth and development. Šíp et al. (2011) reported that central European winter wheat cultivars registered between 1976 and 2009 were specifically adapted to regions with different climatic conditions.

Crop satellite monitoring using multi-temporal images helped to establish that reproductive wheat growth after the flowering stage is closely related to grain yield, as the NDVI values after the flowering stage reflected crop yields (Benedetti and Rossini, 1993; Zhang et al., 2004; Du and Noguchi, 2017). In the currently changing climatic conditions, the knowledge of actual wheat growth status allows for the appropriate agronomy decisions to be taken (Wu et al., 2016; Du and Noguchi, 2017).

In our study, we assessed the spectral response of winter wheat using satellite images acquired during 4 growing seasons $(2005,2009,2011$ and 2013); in addition, spring wheat grown in 2017 was also included in the study. The evaluation was based on the NDVI spectral index, the crop yield frequency map, the actual crop yield, the topography wetness index as well as temperature and precipitation meteorological data. The primary objective was to determine the importance of individual yield influencing factors on wheat yields and to establish the most suitable method of estimating wheat yields in relation to a changing climate.

The secondary objective was to compare the agricultural applicability of Sentinel 2 MSI and Landsat 8 OLI satellite images and to establish which of the available near-infrared bands used by the Sentinel 2 MSI sensor is more suitable for NDVI calculation focused on agricultural applications.

\section{MATERIALS AND METHODS}

The 11.5ha long-term wheat crop study area is located in Prague-Ruzyně in the Czech Republic at $50^{\circ} 05^{\prime} \mathrm{N}$, $14^{\circ} 17^{\prime} 30^{\prime \prime}$ E. The predominant soil type is Haplic Luvisol and the elevation ranges from 338.5 to $357 \mathrm{~m}$ a.s.l. with a southern aspect and $6 \%$ average slope. Detailed information concerning this experimental field is included in (Kumhálová and Moudrý, 2014). The predominant management practices are based on the conventional arable soil tillage technology of ploughing. While fixed crop rotation has been under scientific control since 2001, this research only assessed winter wheat data from 2005, 2009, 2011 and 2013 and two spring wheat cultivars in 2017. 
The winter wheat yield in the years 2005 and 2013 was determined by a Sampo combine harvester with an LH 500 yield monitor (LH Agro, Denmark). This was equipped with a DGPS receiver and an EGNOS correction, which had an accuracy of \pm 0.1 to $0.6 \mathrm{~m}$. The yield data was saved with coordinates to an on-board computer every $3 \mathrm{~s}$. The original yield data was then processed by a common statistical procedure in ArcGIS 10.4.1 (ESRI, Redlands, CA, USA) and GS+ (Gamma Design Software, St. Painwell, MI, USA) SW. A detailed description of this methodology is included in Kumhálová et al. (2011). The 2017 spring wheat yield was measured by a Case IH AF 9230 combine harvester equipped with a AFS Pro 700 yield monitor (Case $\mathrm{IH}, \mathrm{CNH}$ Industrial) and a DGPS receiver with EGNOS correction. The accuracy of this system was \pm 0.1 to $0.2 \mathrm{~m}$. The yield data was saved with coordinates to an on-board computer every second in this case.

Small grain crop yields were measured from 2004 in our experimental field. For this reason, there were no problems with creating a yield frequency map from this data. The yield frequency map reflects long-term yield trends, which is valuable information for the purposes of this arti-

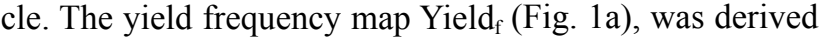
from the yield maps of small grain crops measured from 2004 to 2018 , a total of 8 years when the yield data from the small grain crops were available. In other years, oilseed rape was grown or the yield monitor did not work. The absolute values of the crop yields were re-calculated to relative values (equation) and united in one raster layer using a cell statistics tool. The variable maximum value for the resulting raster was set in order to determine the productivity of this field.
Yield frequency map (\%):

$$
\text { Yield }_{f}=\frac{\text { Yield pixel }}{\text { averageYield plot }_{\text {plo }}} 100
$$

where: the Yield pixel is the actual value of the pixel and the average Yield plot is the average value of the whole plot in the surveyed year.

For the purposes of this article, our experimental field was divided onto two parts (upper and lower) according to topographic attributes (elevation, topography wetness index) and field cultivation technology (prevailing direction of agriculture machinery passes). The Czech Office for Surveying kindly provided LiDAR elevation data for this purpose. The average elevation of the upper part of the field was $349.04 \mathrm{~m}$ a.s.l. (range 342.09 - $356.41 \mathrm{~m}$ a.s.l.) and the lower part was $340.48 \mathrm{~m}$ a.s.l. (range $337.43-346.42 \mathrm{~m}$ a.s.l.). The division of the experimental field into the upper and lower parts is shown in Fig. 2. The TWI is a nondimensional relative index derived from the slope and flow accumulation model; with higher TWI values indicating water availability. In 2017, different spring wheat cultivars were grown on the two parts of the field.

All topography models were created in ArcGIS 10.4.1 SW; and a detailed description is covered in Kumhálová et al. (2014). The total monthly precipitation and temperature data comes from the Crop Research Institute's agro-meteorological station in Prague-Ruzyne, and Table 1 lists the precipitation rates and temperatures for the observed years from the Agrometeorological station (2018) in the Crop Research Institute.

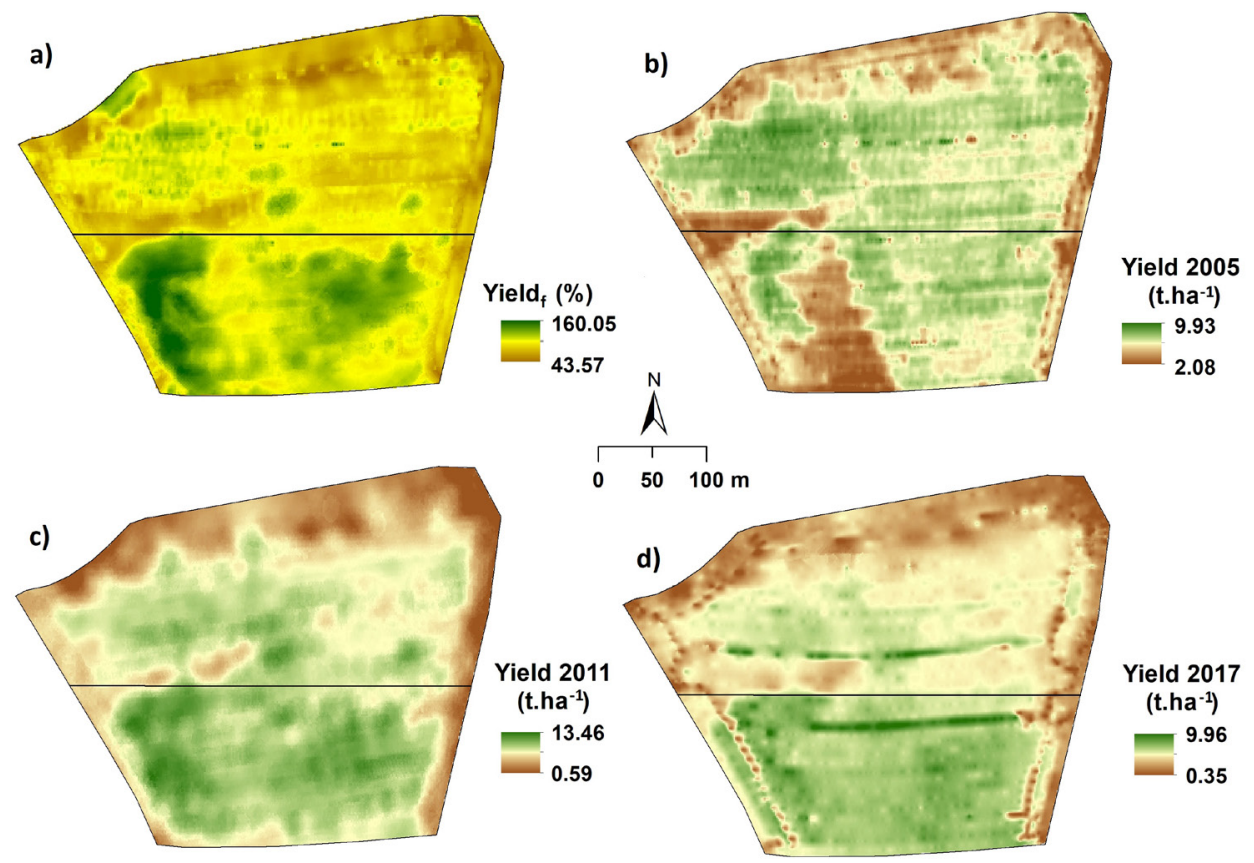

Fig. 1. Yield frequency map (a), winter wheat yield of 2005 (b), winter wheat yield of 2011 (c), winter wheat yield of 2017 (d). 


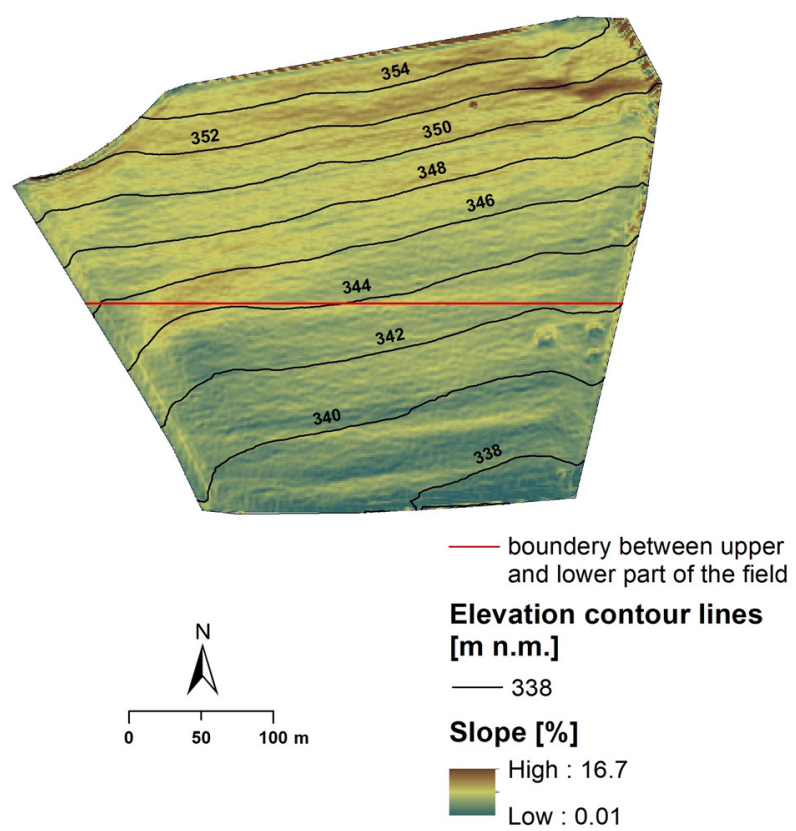

Fig. 2. Division of experimental plot onto upper and lower part according to topographic attributes (elevation, topography wetness index) and field cultivation technology (prevailing direction of agriculture machinery passes).

The winter wheat cultivars of Ebi in 2005 and 2009, Baletka in 2011 and Brilliant in 2013 were grown on the experimental field. Of these, Ebi is a late winter wheat cultivar, moderately tilled and therefore high-standing, with the added advantage of resistance to Fusarium Head Blight and medium frost resistance. The major risk is susceptibility to attack by Blumeria graminis, Monographella nivalis, Puccinia triticina and Zymoseptoria tritici (Winter wheat cultivar Ebi, 2018).

Baletka is an early midwinter cultivar, with low plants and very good resistance to crop lodging. This cultivar provides medium resistance to fusariosis and frost and has a high bulk density, but the weak point is a low resistance to Monographella nivalis attack.

Brilliant, meanwhile, is a semi-late cultivar, with low plants and medium frost resistance, it presents medium resistance to Monographella nivalis (Winter wheat cultivars Baletka and Brilliant, 2018).

As stated previously, two spring wheat cultivars were also grown on the experimental field in 2017; Seance on the upper part of the field and Astrid on the lower portion. Seance is a cultivar with extremely high grain yields in both treated and untreated experimental variants in all production areas. It is very tolerant to short-term drought, and plants reach a medium to lower height with intensive offshoots. It is also suitable for early sowing because it is resistant to both low temperature and Blumeria graminis attack. Moreover, this cultivar provides a high grain yield and quality in Czech Republic conditions (Spring wheat cultivars Seance 2018). In contrast, remote sensing data
Table 1. Precipitations and temperatures at different growth stages by $\mathrm{BBCH}$ scale recorded in the experimental field for winter wheat in 2005, 2011, 2013, and for spring wheat in 2017

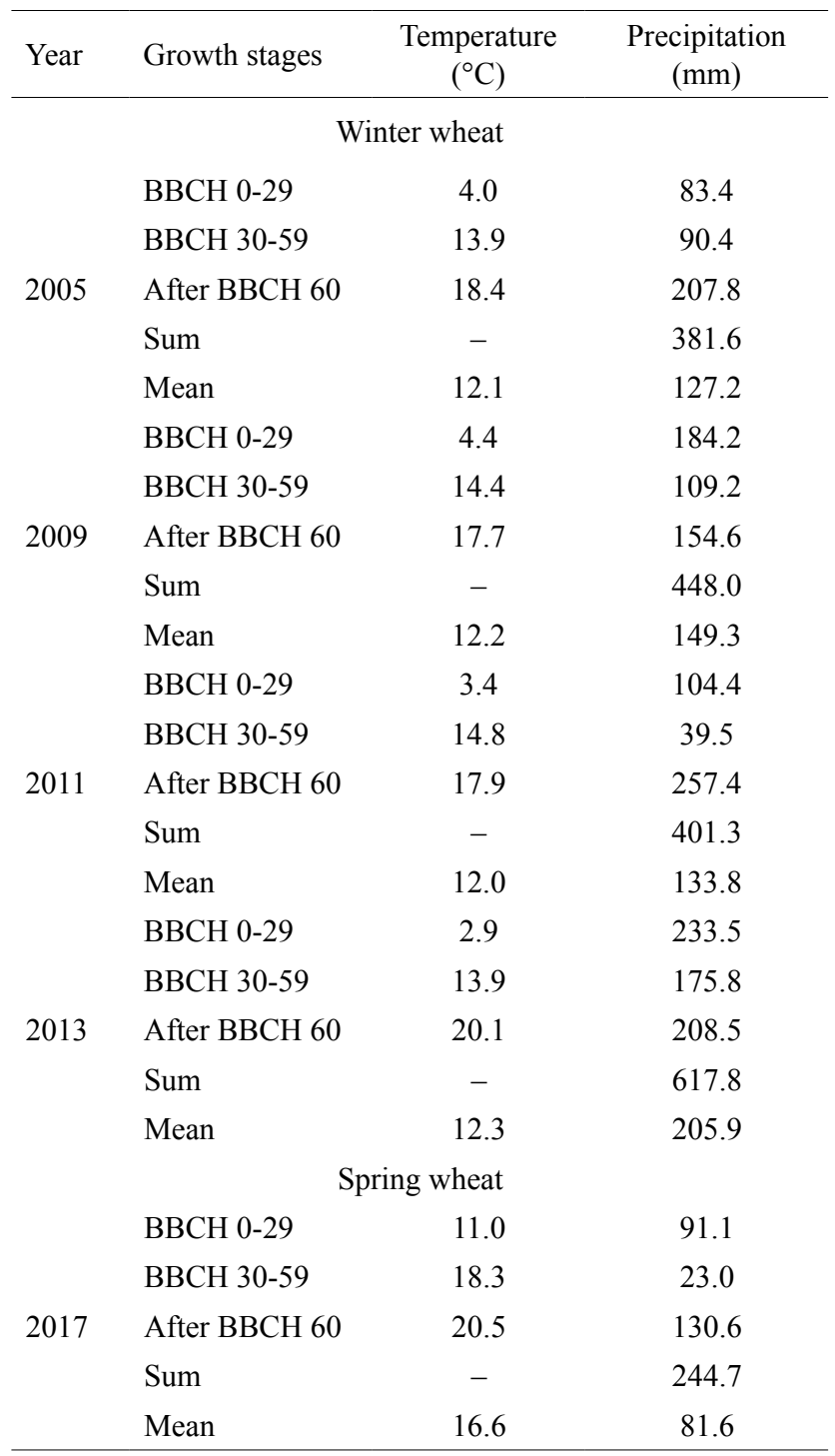

confirms that Astrid is a half-grown cultivar with very good resistance to crop lodging. It is also resistant to Blumeria graminis and is a very common cultivar in the Czech Republic (Spring wheat cultivars Astrid, 2018).

Landsat images were downloaded from US Geological Survey (USGS) storage at C1 Level-1 (Top-Of-Atmosphere reflectances in cartographic geometry) (USGS, 2018). Fast Line-of-Sight Atmospheric Analysis of the Hypercubes module in ENVI SW was used for the atmospheric correction of images; as in (Domínguez et al., 2015, 2017). Table 2 provides the last cloud-free images available in the crop vegetation period for 2005, 2009, 2011, 2013 and 2017 crops. Landsat 5 carried the TM sensor and comprised seven spectral bands, including a thermal band. The Eightband Landsat 7 had the ETM+ instrument. Unfortunately, there was a failure on the Scan Line Corrector on 31st May 
Table 2. Last cloud-free satellite images available in the crop vegetation period at BBCH crop phenological stages

\begin{tabular}{llcclc}
\hline Satellite & Sensor & $\begin{array}{c}\text { RED range } \\
(\mathrm{nm})\end{array}$ & $\begin{array}{c}\text { NIR range } \\
(\mathrm{nm})\end{array}$ & Date & BBCH stage \\
\hline Landsat 5 & TM & $630-690$ & $760-900$ & 3-June 2005 & 61 \\
& & & 14-June 2009 & 69 \\
Landsat 7 & ETM+ & $630-690$ & $770-900$ & 28-June 2011 & 60 \\
Landsat 8 & OLI & $636-673$ & $851-879$ & 16-June 2013 & 70 \\
& & & & 11-June 2017 & 55 \\
& & & & 20-June 2017 & 65 \\
Sentinel 2 & MSI & \multirow{2}{*}{$650-680$} & 785-899 (B8) & 10-June 2017 & 55 \\
& & & $855-875(\mathrm{~B} 8 \mathrm{~A})$ & 20-June 2017 & 65 \\
\hline
\end{tabular}

RED - reflectance in RED band, NIR - reflectance in NIR bands (in B8 and B8A for MSI), TM - Thematic Mapper, ETM+ enhanced thematic mapper plus, OLI - operational land imager, MSI - multispectral instrument.

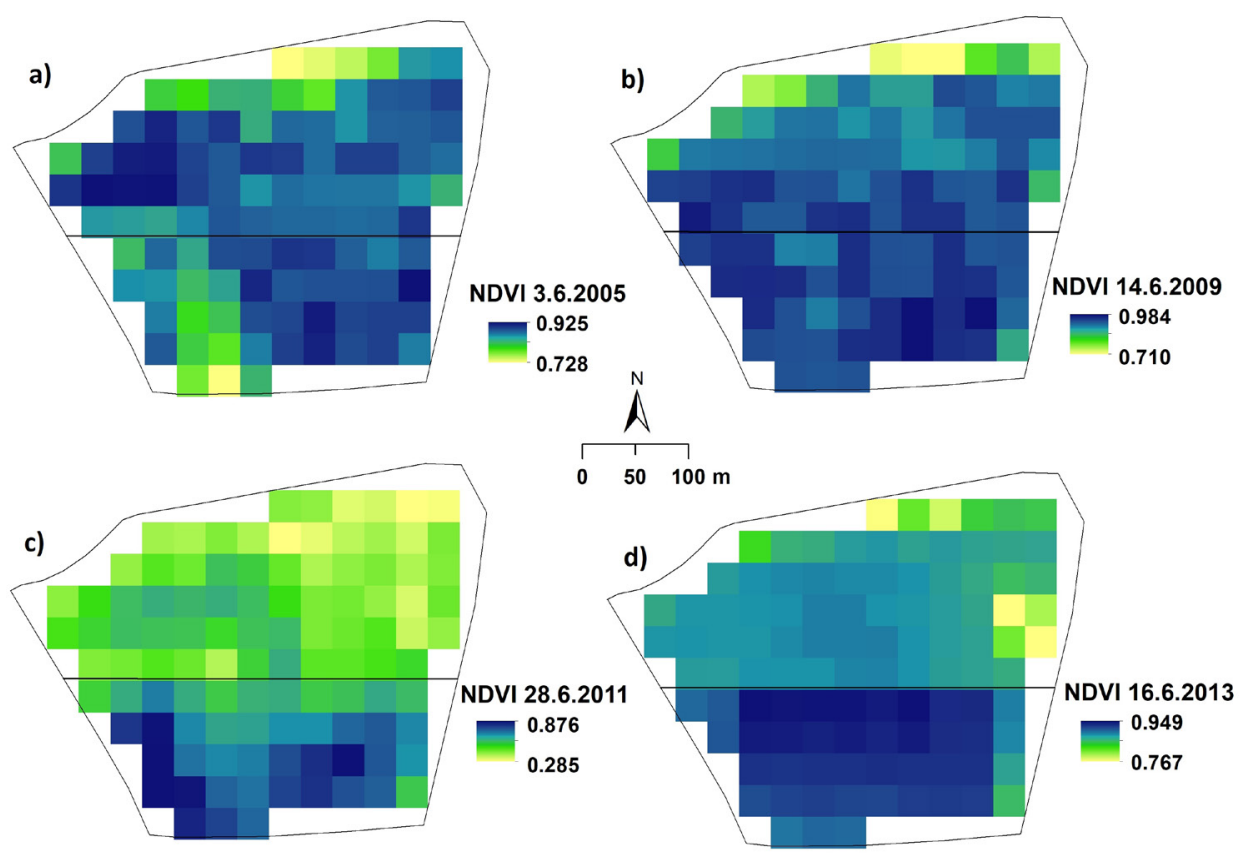

Fig. 3. Normalized difference vegetation index (NDVI) for 3 June 2005 (a), 14 June 2009 (b), 28 June 2011 (c), 16 June 2013 (d).

2003. At present, Landsat 8 is the most recently launched Landsat satellite. The Landsat 8 payload consists of two science instruments - the Operational Land Imager (OLI) and the Thermal Infrared Sensor (TIRS). Landsat 8 OLI comprises eleven spectral bands (NASA, 18.2. 2020: https://landsat.gsfc.nasa.gov/) (Landsat Science, 2020).

Sentinel 2A MSI images were obtained from the Copernicus Open Access Hub by ESA at the 2A level (Bottom-Of-Atmosphere reflectances in cartographic geometry; https://scihub.copernicus.eu/). The Copernicus Sentinel 2 mission comprises a constellation of two polarorbiting satellites - Sentinel 2A and Sentinel 2B with a pushbroom sensor MSI. S2 images have a better spectral resolution in comparison with Landsat products. It comprises 13 spectral bands (https://sentinels.copernicus.eu/web/sen- tinel/missions/sentinel-2) (Sentinel Online 2020). Selected images were pre-processed in SW SNAP 6.0. In the case of the Sentinel 2 images, NDVI was calculated for both NIR bands (B8 and B8A) in order to establish which band results are better for NDVI calculation. Figures 3 and 5 show that NDVI spectral index calculations and ENVI 5.5 remote sensing software processed all of the images (Excelis, Inc., McLean, USA). The resulting rasters of actual yield, the yield frequency map and TWI and Sentinel 2 images were re-sampled in two spatial resolutions according to Landsat 8 images $(30 \mathrm{~m})$ and Sentinel 2 images $(10 \mathrm{~m})$. Only pixels completely inside plots and without clouds were considered, and the rasters were analysed using SW's ArcGIS 10.4.1 and Statistica 8.0. 


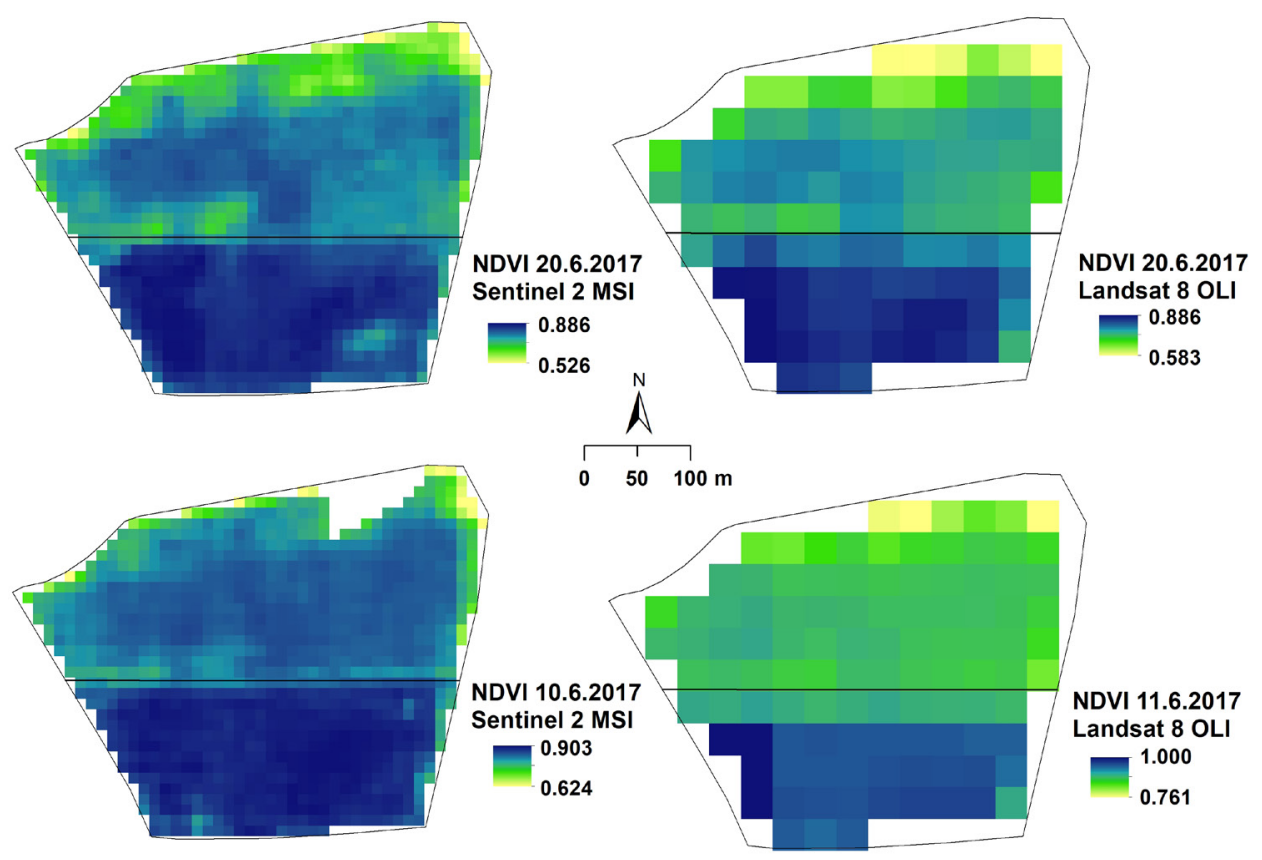

Fig. 4. Normalized difference vegetation index (NDVI, calculated with B8 band for NIR) for 10 June 2017 from Sentinel 2 MSI - the north part of the field is deleted due to cloudiness (a), 11 June 2017 from Landsat 8 OLI (b), 20 June 2017 from Sentinel 2 MSI (c), 20 June 2017 from Landsat 8 OLI (d).

\section{RESULTS AND DISCUSSION}

Table 3 provides a summary of the NDVI statistics from the selected years of 2005, 2009, 2011, 2013 and 2017, and also the satellite images are divided into the upper and lower parts as well as the whole experimental field. A summary of the crop yield statistics for 2005, 2011 and 2017 are divided into upper and lower areas and also the whole experimental field and listed in Table 4. A visualization of the calculated yield frequency map and measured wheat yields in the years 2005, 2011 and 2017 may be seen in Fig. 2.

As may be seen from Table 1, winter wheat was grown on our experimental field in these years. In 2005 and 2009, the variety was Ebi, in 2011 the variety Baletka was grown and in 2013 the variety grown was Brilliant. Figure 3 shows the NDVI spectral index calculations for those years.

The 2005 Ebi winter wheat cultivar satellite images were acquired on June 3 from BBCH 61 at the flowering commencement. The summary statistics for the NDVI statistics revealed similar values in both parts of the field (see Table 3). Although the winter wheat canopy on the entire field was more uniform than in the other years monitored, precipitation distribution, water supply and management zones with different nitrogen fertilizer application were the most important factors in determining this cultivar's yield (Kumhálová et al., 2008; Matějková et al., 2010). Moreover, they caused a significant displacement of the relatively higher yield to the upper part of the field (Table 4).
This finding is also confirmed in Fig. 4a by the inde-

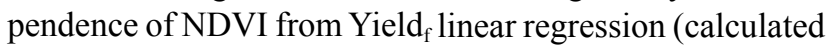
$\mathrm{R}^{2}=0.08$ ), which means that the distribution of the yield on the experimental field was very different from the other reference years. On the other hand, the relationship of NDVI with the Yield was measured in 2005 by combining the existing yield monitor with the calculated coefficient of determination $\mathrm{R}^{2}=0.44$ (Fig. $4 \mathrm{e}$ ).

The 2009 Ebi winter wheat cultivar satellite images were acquired on June 14 from the BBCH 69 flowering cessation. Table 1 illustrates that precipitation distribution and water supply were uniform throughout the vegetation season and that the NDVI winter wheat values on the upper part of the plot had a greater dependence on the water supply as represented by TWI $\left(\mathrm{R}^{2}=0.51\right)$ than the lower part which had better water availability (NDVI depended on TWI only from $4 \%$ on the lower part (Table 5 ).

The 2009 Yield $_{\mathrm{f}}$ and NDVI values in Table $5\left(\mathrm{R}^{2}=0.29\right.$ for the whole field) were relatively low compared to other years, and Table 3 indicates higher NDVI summary values. While crops in the higher part of the research area had a higher standard deviation, those in the lower part were more uniform. As a result of sufficient rainfall in 2009, the winter wheat crop on both parts of the experimental field was well balanced and, consequently, there was a significant difference between Yield $_{f}$ and NDVI values. The yield map from a combine harvester was unfortunately not available for this year. However, based on the favourable distribution of rainfall, it may be assumed that NDVI in 2009 would 
Table 3. Summary statistics of NDVI for selected years (2005, 2009, 2011, 2013 and 2017) divided to upper / lower part and the whole experimental plot

\begin{tabular}{|c|c|c|c|c|c|c|c|c|c|}
\hline Date & Sensor & $\begin{array}{l}\text { Part } \\
\text { of plot }\end{array}$ & Count & Mean & Median & $\begin{array}{l}\text { Standard } \\
\text { deviation }\end{array}$ & Min & Max & Skewness \\
\hline \multirow{3}{*}{3 June 2005} & \multirow{3}{*}{ L5 } & Upper & 64 & 0.864 & 0.874 & 0.037 & 0.728 & 0.925 & -1.575 \\
\hline & & Lower & 41 & 0.866 & 0.879 & 0.035 & 0.754 & 0.911 & -1.353 \\
\hline & & Whole & 105 & 0.865 & 0.875 & 0.036 & 0.728 & 0.925 & -1.482 \\
\hline \multirow{3}{*}{14 June 2009} & \multirow{3}{*}{ L5 } & Upper & 64 & 0.907 & 0.922 & 0.057 & 0.710 & 0.973 & -1.793 \\
\hline & & Lower & 42 & 0.947 & 0.945 & 0.020 & 0.880 & 0.984 & -0.779 \\
\hline & & Whole & 106 & 0.923 & 0.937 & 0.050 & 0.710 & 0.984 & -2.224 \\
\hline \multirow{3}{*}{28 June 2011} & \multirow{3}{*}{ L7 } & Upper & 64 & 0.499 & 0.488 & 0.075 & 0.285 & 0.644 & 0.001 \\
\hline & & Lower & 42 & 0.727 & 0.729 & 0.088 & 0.565 & 0.876 & -0.102 \\
\hline & & Whole & 106 & 0.589 & 0.576 & 0.138 & 0.285 & 0.876 & 0.344 \\
\hline \multirow{3}{*}{16 June 2013} & \multirow{3}{*}{ L8 } & Upper & 64 & 0.878 & 0.888 & 0.031 & 0.767 & 0.902 & -2.172 \\
\hline & & Lower & 42 & 0.928 & 0.934 & 0.018 & 0.866 & 0.949 & -1.520 \\
\hline & & Whole & 106 & 0.898 & 0.896 & 0.036 & 0.767 & 0.949 & -1.219 \\
\hline \multirow{3}{*}{10 June 2017} & \multirow{3}{*}{$\mathrm{S} 2$} & Upper & 623 & 0.825 & 0.841 & 0.041 & 0.624 & 0.864 & -2.381 \\
\hline & & Lower & 414 & 0.881 & 0.887 & 0.019 & 0.777 & 0.903 & -2.627 \\
\hline & & Whole & 1037 & 0.848 & 0.850 & 0.041 & 0.642 & 0.903 & -1.604 \\
\hline \multirow{3}{*}{11 June 2017} & \multirow{3}{*}{ L8 } & Upper & 63 & 0.915 & 0.927 & 0.042 & 0.761 & 0.967 & -2.153 \\
\hline & & Lower & 42 & 0.985 & 0.999 & 0.048 & 0.940 & 1.000 & -0.335 \\
\hline & & Whole & 105 & 0.959 & 0.943 & 0.071 & 0.761 & 1.000 & 0.030 \\
\hline \multirow{3}{*}{20 June 2017} & \multirow{3}{*}{$\mathrm{S} 2$} & Upper & 653 & 0.750 & 0.771 & 0.062 & 0.526 & 0.829 & -1.183 \\
\hline & & Lower & 409 & 0.844 & 0.850 & 0.028 & 0.721 & 0.886 & -1.398 \\
\hline & & Whole & 1062 & 0.787 & 0.795 & 0.067 & 0.526 & 0.886 & -1.025 \\
\hline \multirow{3}{*}{20 June 2017} & \multirow{3}{*}{ L8 } & Upper & 64 & 0.744 & 0.759 & 0.055 & 0.583 & 0.808 & -1.237 \\
\hline & & Lower & 42 & 0.844 & 0.854 & 0.032 & 0.756 & 0.886 & -0.883 \\
\hline & & Whole & 106 & 0.784 & 0.788 & 0.069 & 0.583 & 0.886 & -0.708 \\
\hline
\end{tabular}

L8 = Landsat 8, S2 = Sentinel 2 .

Table 4. Summary statistics of crop yield $\left(\mathrm{t} \mathrm{ha}^{-1}\right)$ for selected years $(2005,2011$ and 2017) divided to upper / lower part and the whole experimental plot

\begin{tabular}{|c|c|c|c|c|c|c|c|c|}
\hline \multirow[b]{2}{*}{ Year } & \multirow{2}{*}{$\begin{array}{l}\text { Part } \\
\text { of plot }\end{array}$} & \multicolumn{7}{|c|}{ Yield } \\
\hline & & Count & Mean & Median & $\begin{array}{l}\text { Standard } \\
\text { deviation }\end{array}$ & Minimum & Maximum & Skewness \\
\hline \multirow{3}{*}{2005} & Upper & 4973 & 6.17 & 6.38 & 1.16 & 2.08 & 9.93 & -0.84 \\
\hline & Lower & 3263 & 5.95 & 6.22 & 1.17 & 2.09 & 9.37 & -0.75 \\
\hline & Whole & 8236 & 6.08 & 6.32 & 1.14 & 2.075 & 9.93 & -0.81 \\
\hline \multirow{3}{*}{2011} & Upper & 4442 & 6.46 & 6.69 & 1.83 & 0.59 & 13.36 & -0.10 \\
\hline & Lower & 3106 & 7.90 & 7.95 & 1.80 & 0.67 & 13.46 & -0.28 \\
\hline & Whole & 7548 & 7.05 & 7.22 & 1.95 & 0.59 & 13.46 & -0.14 \\
\hline \multirow{3}{*}{2017} & Upper & 4277 & 4.21 & 4.57 & 1.43 & 0.35 & 9.93 & -0.35 \\
\hline & Lower & 3405 & 5.94 & 6.26 & 1.53 & 0.37 & 9.96 & -1.29 \\
\hline & Whole & 7682 & 4.98 & 5.16 & 1.70 & 0.35 & 9.96 & -0.42 \\
\hline
\end{tabular}




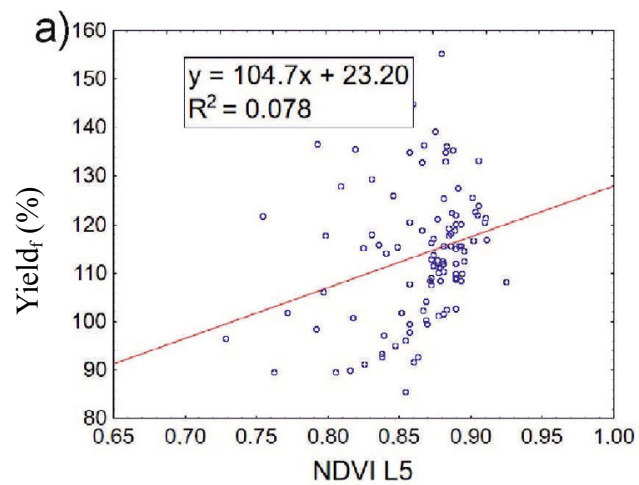

b)

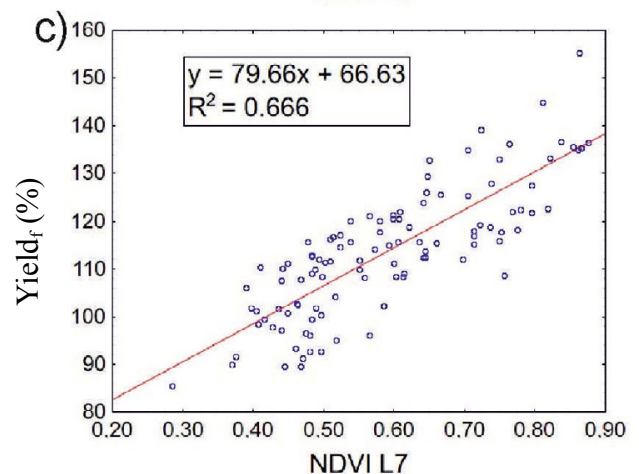

d)
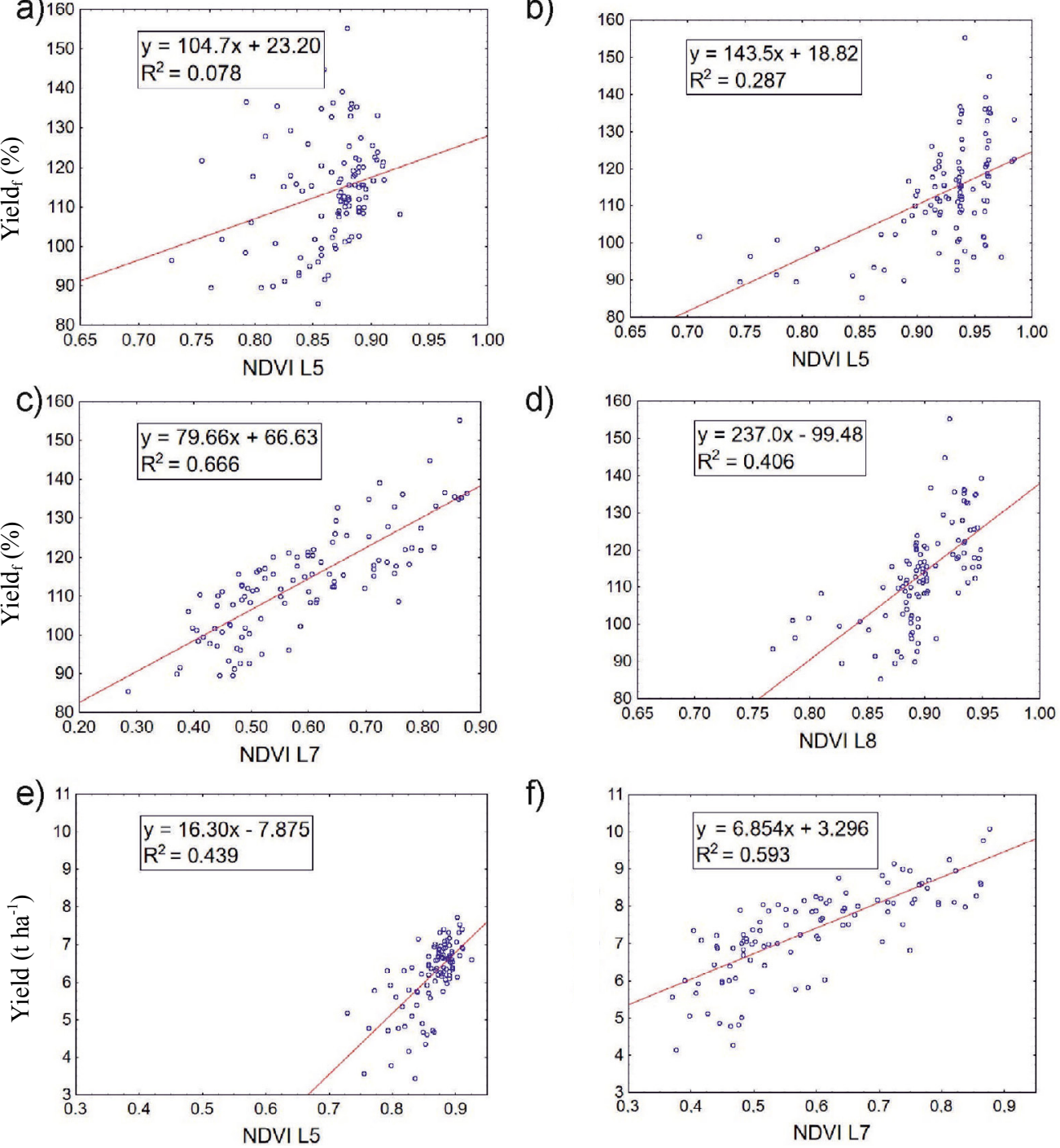

f)

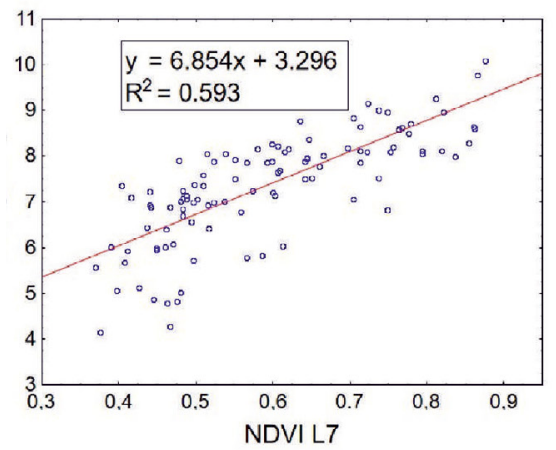

Fig. 5. Coefficients of determination $\left(\mathrm{R}^{2}\right)$ of the whole field for the year 2005 between Yield $_{\mathrm{f}}$ and NDVI from Landsat 5 (a), for 2009 between Yield $_{\mathrm{f}}$ and NDVI from Landsat 5 (b), for 2011 between Yield ${ }_{\mathrm{f}}$ and NDVI from Landsat 7 (c), for 2013 between Yield $_{\mathrm{f}}$ and NDVI from Landsat 8 (d), for 2005 between Yield and NDVI from Landsat 5 (e), for 2011 between Yield and NDVI from Landsat 7 (f).

characterize the yield from individual parts of the field better than the relevant yield frequency map. Therefore, if a yield map is not available, NDVI provides very valuable additional information about yield distribution throughout the field as opposed to a yield frequency map.

The 2011 satellite images for Baletka winter wheat were acquired on June 28, and were related to BBCH 77. There was imbalanced precipitation distribution, with the highest value of $257.4 \mathrm{~mm}$ recorded in growth stages after $\mathrm{BBCH} 60$ in late July. This contrasted sharply with the $39.4 \mathrm{~mm}$ drought level registered in the $\mathrm{BBCH} 30-59$ growth periods. The yield distribution in 2011 corresponded well with the yield frequency map $\left(\mathrm{R}^{2}=0.68\right.$, Table 5). This situation was also reflected to a significant extent by satellite image, when the Yield $_{f} / \mathrm{NDVI}$ correlation coefficient produced a result of 0.67 and Yield/NDVI was 0.59 (Table 5, Fig. 2c, 3c).
The differences between the upper and lower parts of the plot as well as TWI and NDVI/Yield comparisons were non-significant (Table 5), and while summary NDVI statistics identified significant differences between the upper and lower area values, there was only a small difference in standard deviations. These differences are explained by the influence of drought on the winter wheat canopy during $\mathrm{BBCH} 30-59$ and by the nutrient supply redistributed by rain-water flow to accumulations in the lower part of the field. However, during the second half of July rainfall had no effect on yield or production quality.

The 2013 satellite images for the Brilliant winter wheat cultivar were acquired on June 16 and related to BBCH 70 . Precipitation was high during this vegetation season, reaching $617.8 \mathrm{~mm}$. This value corresponds to the statistics in Tables 3 and 5 and Fig. 4. Figure 3 indicates uniform summary statistical differences between the upper and lower 
Table 5. Coefficients of determination between topography wetness index (TWI) and normalised difference vegetation index

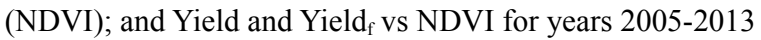

\begin{tabular}{|c|c|c|c|c|}
\hline \multirow{2}{*}{$\begin{array}{l}\text { Sensor/ } \\
\text { Variety }\end{array}$} & \multirow{2}{*}{$\begin{array}{l}\text { Coefficients of } \\
\text { determination }\end{array}$} & \multicolumn{3}{|c|}{ Part of field } \\
\hline & & Upper & Lower & Whole \\
\hline \multicolumn{5}{|c|}{3 June 2005} \\
\hline \multirow{5}{*}{$\begin{array}{l}\text { L5 } \\
\text { Ebi }\end{array}$} & TWI/NDVI & 0.267 & 0.129 & 0.059 \\
\hline & TWI/Yield & 0.031 & 0.014 & 0.004 \\
\hline & Yield/NDVI & 0.378 & 0.619 & 0.440 \\
\hline & Yield $_{\mathrm{f}} / \mathrm{NDVI}$ & 0.398 & 0.004 & 0.078 \\
\hline & Yield/Yield ${ }_{\mathrm{f}}$ & 0.588 & 0.028 & 0.048 \\
\hline \multicolumn{5}{|c|}{14 June 2009} \\
\hline \multirow{5}{*}{$\begin{array}{l}\text { L5 } \\
\text { Ebi }\end{array}$} & TWI/NDVI & 0.509 & 0.043 & 0.396 \\
\hline & TWI/Yield & - & - & - \\
\hline & Yield/NDVI & - & - & - \\
\hline & Yield $_{\mathrm{f}} / \mathrm{NDVI}$ & 0.243 & 0.099 & 0.287 \\
\hline & Yield/Yield & - & - & - \\
\hline \multicolumn{5}{|c|}{28 June 2011} \\
\hline \multirow{5}{*}{$\begin{array}{c}\text { L7 } \\
\text { Baletka }\end{array}$} & TWI/NDVI & 0.106 & 0.085 & 0.124 \\
\hline & TWI/Yield & 0.257 & 0.256 & 0.293 \\
\hline & Yield/NDVI & 0.509 & 0.319 & 0.593 \\
\hline & Yield $_{\mathrm{f}} / \mathrm{NDVI}$ & 0.494 & 0.434 & 0.666 \\
\hline & Yield/Yield $_{f}$ & 0.634 & 0.452 & 0.684 \\
\hline \multicolumn{5}{|c|}{16 June 2013} \\
\hline \multirow{5}{*}{$\begin{array}{l}\text { L8 } \\
\text { Brilliant }\end{array}$} & TWI/NDVI & 0.088 & 0.13 & 0.129 \\
\hline & TWI/Yield & - & - & - \\
\hline & Yield/NDVI & - & - & - \\
\hline & Yield $_{\mathrm{f}} / \mathrm{NDVI}$ & 0.190 & 0.089 & 0.406 \\
\hline & Yield/Yield ${ }_{\mathrm{f}}$ & - & - & - \\
\hline
\end{tabular}

Landsat 5-8 was compared in spatial resolution $30 \mathrm{~m}$; Sentinel 2 in $10 \mathrm{~m}$. All coefficients are at 5\% significance level.

parts of the plot. Although NDVI registered higher values in the lower portion of the plot, its higher standard deviation in the upper part of the plot recorded the lowest values of all the years monitored. This NDVI inconsistency in the field areas visibly divided the upper and lower parts of the plot (Fig. 1). The accompanying lower average value in the TWI and NDVI determinations was most likely due to higher 2013 water availability compared to other years. Finally, the Yield $_{f} /$ NDVI ratio registered a higher dependence in the upper field portion of the plot.

The 2017 satellite images (Fig. 5) for the evaluation of spring wheat were acquired at similar times; on June 10 for Sentinel 2, June 11 for Landsat 8 and for both sensors on June 20, and these are therefore comparable. The June 10/11 2017 evaluations were for the BBCH 55 middle of the heading. NDVI crop growth values are explained by TWI from $25 \%\left(\mathrm{R}^{2}=0.50\right)$ for $\mathrm{S} 2$ and $13 \%$ for $\mathrm{L} 8$; NDVI may also be explained by $48 \%$ (S2) and 59\% (L8) in Yield $_{f}$
Table 6. Coefficients of determination between topography wetness index (TWI) and normalised difference vegetation index

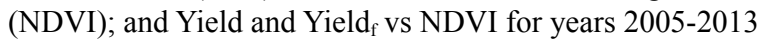

\begin{tabular}{|c|c|c|c|c|}
\hline \multirow{3}{*}{ Sensor } & \multirow{3}{*}{$\begin{array}{l}\text { Coefficients of } \\
\text { determination }\end{array}$} & \multirow{2}{*}{\multicolumn{3}{|c|}{$\begin{array}{c}\text { Part of field } \\
\text { Upper part Seance / } \\
\text { Lower part Astrid }\end{array}$}} \\
\hline & & & & \\
\hline & & Upper & Lower & Whole \\
\hline \multicolumn{5}{|c|}{10 June 2017} \\
\hline \multirow{5}{*}{ S2 } & TWI/NDVI & 0.383 & 0.113 & 0.250 \\
\hline & TWI/Yield & 0.381 & 0.135 & 0.264 \\
\hline & Yield/NDVI & 0.536 & 0.297 & 0.587 \\
\hline & Yield $_{\mathrm{f}} / \mathrm{NDVI}$ & 0.326 & 0.248 & 0.479 \\
\hline & Yield/Yield ${ }_{f}$ & 0.396 & 0.204 & 0.491 \\
\hline \multicolumn{5}{|c|}{11 June 2017} \\
\hline \multirow{5}{*}{ L8 } & TWI/NDVI & 0.347 & 0.0006 & 0.127 \\
\hline & TWI/Yield & 0.274 & 0.063 & 0.192 \\
\hline & Yield/NDVI & 0.399 & 0.025 & 0.503 \\
\hline & Yield $_{\mathrm{f}} / \mathrm{NDVI}$ & 0.367 & 0.159 & 0.593 \\
\hline & Yield/Yield $_{\mathrm{f}}$ & 0.364 & 0.043 & 0.477 \\
\hline \multicolumn{2}{|c|}{ NDVIS2/NDVI L8 } & \multicolumn{3}{|c|}{$\begin{array}{l}0.689(\mathrm{~S} 2 \mathrm{NIR}=\mathrm{B} 8) \\
0.661(\mathrm{~S} 2 \mathrm{NIR}=\mathrm{B} 8 \mathrm{~A})\end{array}$} \\
\hline \multicolumn{5}{|c|}{20 June 2017} \\
\hline \multirow{5}{*}{$\mathrm{S} 2$} & TWI/NDVI & 0.397 & 0.195 & 0.285 \\
\hline & TWI/Yield & 0.381 & 0.135 & 0.264 \\
\hline & Yield/NDVI & 0.674 & 0.231 & 0.653 \\
\hline & Yield $_{\mathrm{f}} / \mathrm{NDVI}$ & 0.511 & 0.479 & 0.615 \\
\hline & Yield/Yield & 0.396 & 0.204 & 0.491 \\
\hline \multicolumn{5}{|c|}{20 June 2017} \\
\hline \multirow{5}{*}{ L8 } & TWI/NDVI & 0.412 & 0.061 & 0.236 \\
\hline & TWI/Yield & 0.274 & 0.063 & 0.192 \\
\hline & Yield/NDVI & 0.530 & 0.150 & 0.642 \\
\hline & Yield $_{\mathrm{f}} / \mathrm{NDVI}$ & 0.497 & 0.282 & 0.653 \\
\hline & Yield/Yield $_{\mathrm{f}}$ & 0.364 & 0.043 & 0.477 \\
\hline \multicolumn{2}{|c|}{ NDVIS2/NDVI L8 } & \multicolumn{3}{|c|}{$\begin{array}{l}0.876(\mathrm{~S} 2 \mathrm{NIR}=\mathrm{B} 8) \\
0.797(\mathrm{~S} 2 \mathrm{NIR}=\mathrm{B} 8 \mathrm{~A})\end{array}$} \\
\hline
\end{tabular}

Landsat 5-8 was compared in spatial resolution $30 \mathrm{~m}$, Sentinel 2 in $10 \mathrm{~m}$. All coefficients are at 5\% significance level.

variability and $59 \%$ (S2) and 50\% (L8) in yield variability (Table 6). Table 3 shows that the mean NDVI value was 0.85 for S2 and 0.96 for L8 over the entire field. The Seance cultivar in the upper portion of the field had a notably higher $\mathrm{R}^{2}$ for all variables (Table 6) and lower NDVI summary mean, median, minimum and maximum values (Table 3) than the Astrid cultivar in the lower plot area. However, a comparison between the S2 and L8 values for the 10th and 11th of June 2017 images reveals more variations than those from the 20th of June, probably because of the oneday scan delay. The NDVI $\mathrm{R}^{2}$ for the Sentinel 2/Landsat 

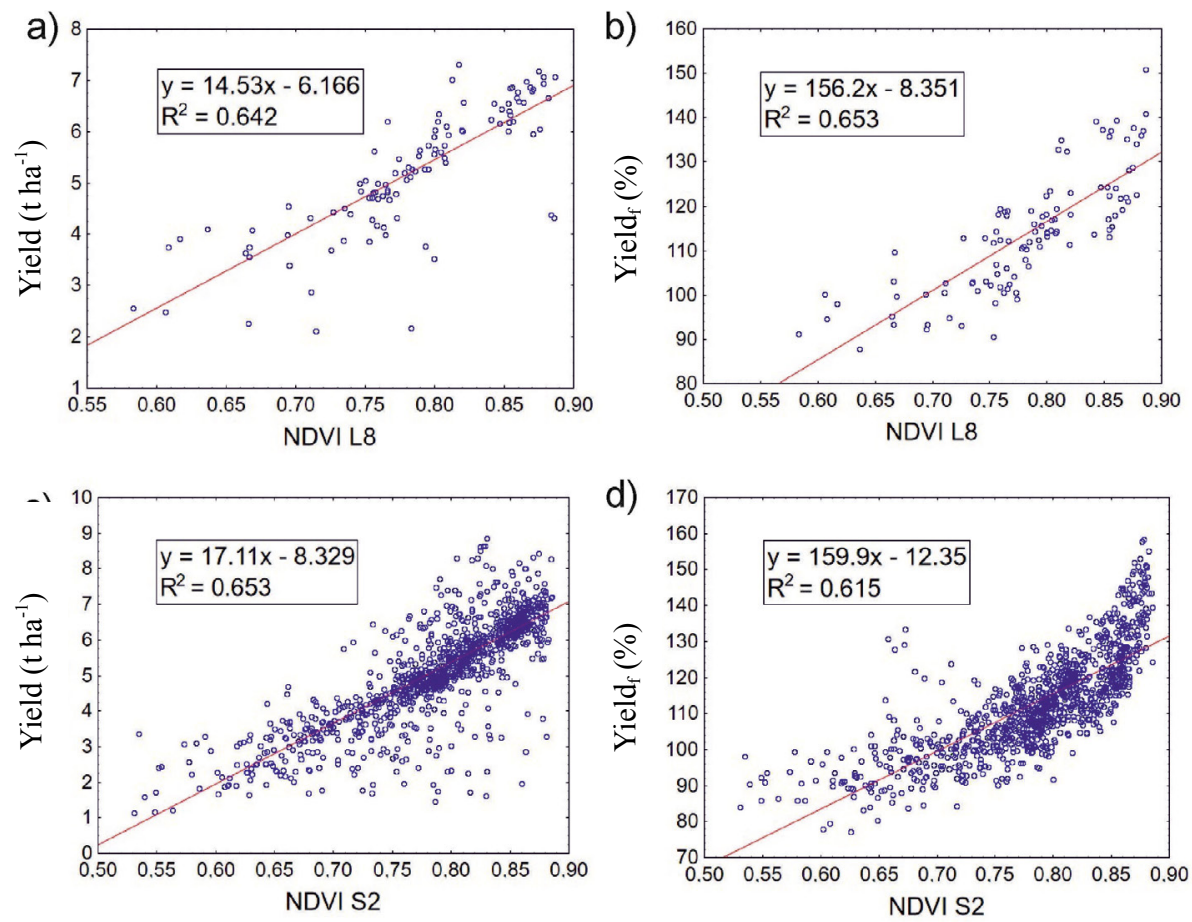

Fig. 6. Coefficients of determination $\left(\mathrm{R}^{2}\right)$ of the whole field for 20 June 2017 - between Yield and NDVI from Landsat 8 (a), Yield ${ }_{\mathrm{f}}$ and

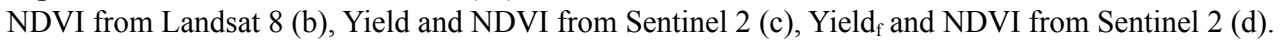

a)

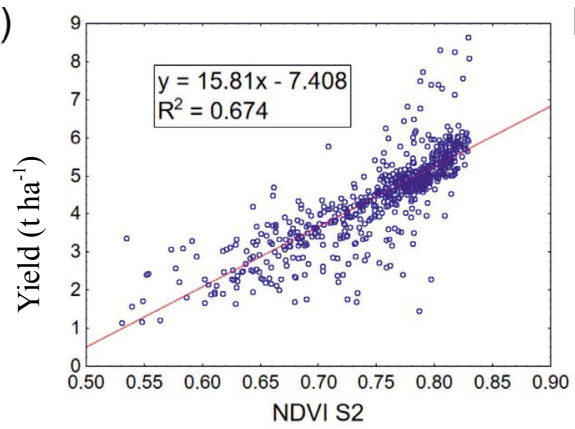

C)

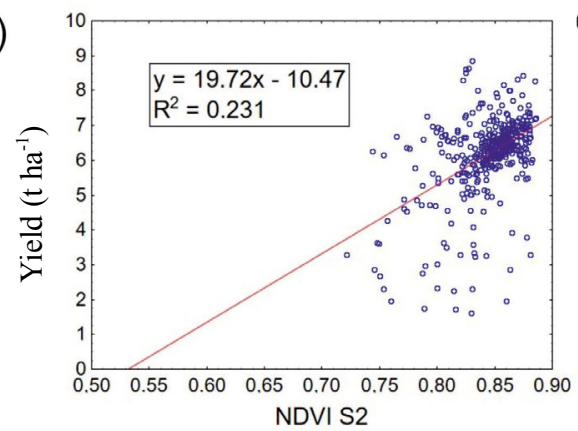

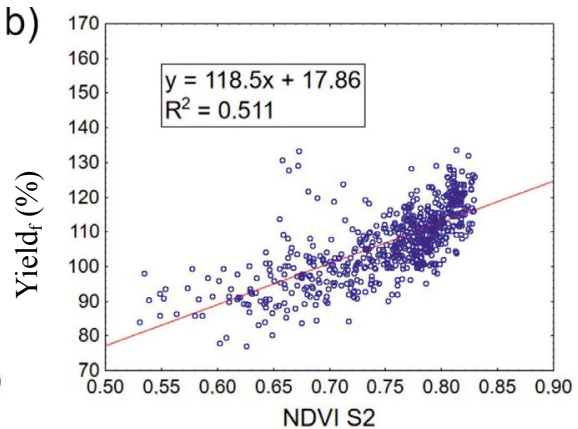

d)

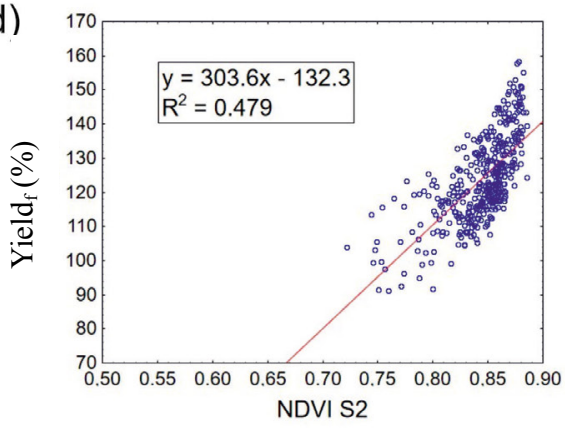

Fig. 7. Coefficients of determination $\left(\mathrm{R}^{2}\right)$ - the upper part of the field for 20 June 2017 from Sentinel 2 between Yield and NDVI (a),

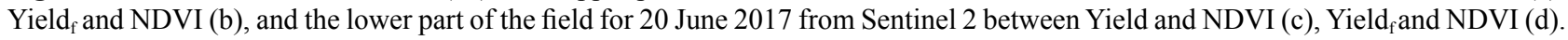

8 for $10 / 11$ of June 2017 was 0.69 , and the next satellite images from these sensors were taken on June 202017 for BBCH 65 flowering. The NDVI $\mathrm{R}^{2}$ for Sentinel 2/Landsat 8 resulted in 0.88 for this day (Table 6). Obviously, the resulting dependence of the observed growth factors on the
Sentinel 2/Landsat 8 satellite data was influenced mainly by spatial resolution $(10 \mathrm{~m} /$ pixel for Sentinel 2 and $30 \mathrm{~m} /$ pixel for Landsat 8) and, in the case of a one-day scan delay, also by another condition of the scanned crop because of the rain on June 9th and 10th and no rain on June 11th. 

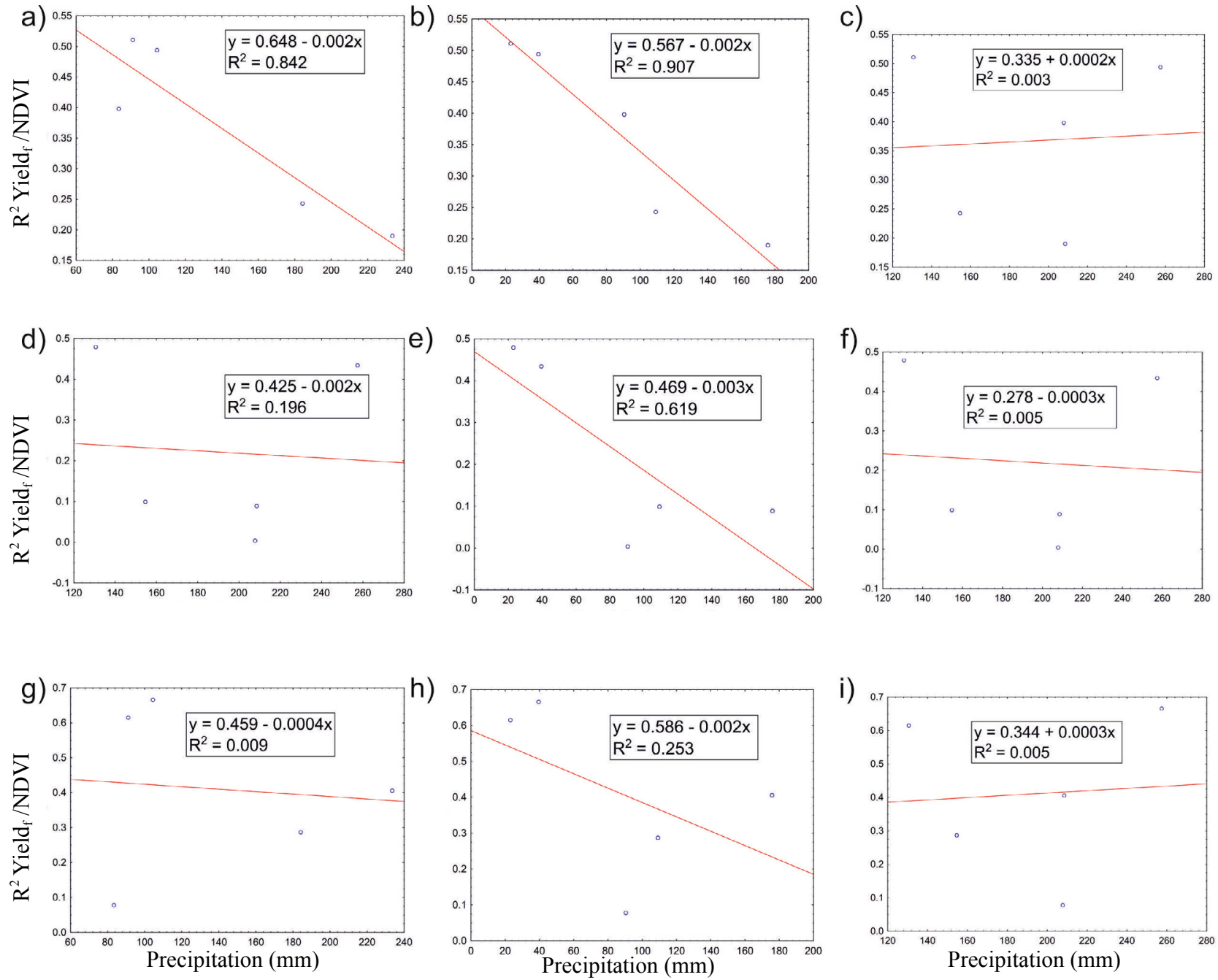

Fig. 8. Coefficients of determination $\left(\mathrm{R}^{2}\right)$ of the upper part of the field for selected years $(2005,2009,2011,2013$ and 2017$)$ between $\mathrm{R}^{2}$ Yield $_{\mathrm{f}} / \mathrm{NDVI}$ and precipitation - in growth stages BBCH 0-29 (a), in BBCH 30-59 (b), in BBCH after 60 (c); $\mathrm{R}^{2}$ of the lower part of the field for selected years between $\mathrm{R}^{2}$ Yield $_{\mathrm{f}} / \mathrm{NDVI}$ and precipitation - in growth stages $\mathrm{BBCH}$ 0-29 (d), in $\mathrm{BBCH} 30-59$ (e), in BBCH after 60 (f); $\mathrm{R}^{2}$ of the whole field for selected years between $\mathrm{R}^{2}$ Yield $\mathrm{f} / \mathrm{NDVI}$ and precipitation - in growth stages BBCH $0-29(\mathrm{~g})$, in BBCH 30-59 (h), in BBCH after 60 (i).

The Wilcoxon test confirmed the statistically significant difference between NDVI derived from Sentinel 2 and the Landsat 8 data for both the upper and lower part of our experimental field at a 0.001 significance level in the case of 10/11 June scanning. On the other hand, this difference was confirmed for the upper part of the field only in the case of the scans of the 20th of June and no significant differences were found in the lower part of the field. This was due to a more even distribution of yield in the lower part of the plot (Fig. 2d). With a higher degree of data resolution from Sentinel 2, the yield variability can be more accurately estimated than from the lower resolution of the Landsat 8 data (Table 6, Yield/NDVI coefficients of determination). On the other hand, a greater generalization of the Landsat 8 data may correlate more with the average yield data from several years as represented by the yield frequency map (Table 6 Yield $_{\mathrm{f}}$ NDVI). The total precipita- tion was $1.3 \mathrm{~mm}$ on June 9, $0.2 \mathrm{~mm}$ on June 10 and there was no rain on June 11. This influenced the resulting crop spectral response values in the summary statistics because water on the plant leaves usually decreases these values in the canopy. In addition, the leaf pigment concentration, water content and structure caused variations in leaf reflectance, transmission and absorption values yield (Scudiero et al., 2014; Van Leeuwen and Huete, 1996), and these differences may be influenced by other crop spectral characteristics and a different range of the red and NIR bands of the sensors (Table 2). The NDVI of the 2017 crop growth values for the 20th of June may be explained by the difference in TWI from $29 \%\left(\mathrm{R}^{2}=0.29\right)$ for $\mathrm{S} 2$ and $24 \%$ for $\mathrm{L} 8$; NDVI was explained by a $62 \% \mathrm{~S} 2$ and $65 \%$ L8 Yield $_{\mathrm{f}}$ variability and a $65 \% \mathrm{~S} 2$ and 64\% L8 yield variability (Table 6). Figure 6 show $\mathrm{s}$ the regression between these variables. 
It is noteworthy that no significant differences were found when comparing the sensor values derived in this study. The weather conditions in 2017 ensured vigorous plant growth and while this corresponded with the yield frequency map for the plot as a complex, Table 6 and Fig. 7 emphasize that the upper part of the field had a higher determination of all of the compared variables. Table 3 shows the lower summary mean, median, minimum and maximum NDVI statistical values in the higher part of the field as opposed to the lower part of the field as noted in the previous comparison. This may have been caused by the cultivar response to stable local conditions. In addition, Table 4 illustrates that the yield in the lower part of the research field was significantly higher than it was in the upper part due to the greater supply of water from water flow accumulation (Kumhálová et al., 2011).

Yield is the most complex and important target in field crops, and challenges still remain in precisely describing this and improving accurate predictions from seasonal data Nearing et al., 2010; Thorp et al., 2001). Further research is required to define the most suitable sensor platform which will improve soil and crop management in different geographical conditions (Flynn et al., 2020). Despite the conclusion of Scudiero et al. (2014) that Landsat spatial resolution was too coarse to capture soil and crop spatial variability, on the basis of our results it may be stated that Landsat imagery was crucial in capturing the historical development of wheat cultivars on this study field.

The influence of topographic characteristics on the 2004-2015 yields was described in detail in previous articles (e.g. Kumhálová and Matějková, 2017; Kumhálová et al., 2011). Therein, it was established that the influence of field topography on crop yield in drier and warmer years was more distinct than in wetter and colder years. This insight is important for the consideration of the warmer and drier year of 2017, where selected Seance and Astrid cultivars exhibited specific properties matching the enforced requirements of different parts of the studied plot. The lower parts were more susceptible to water accumulation, and the effects of this are exemplified in the lower area crop lodging which was reported for the 2010 oat crop during intensive rainfall at the $\mathrm{BBCH} 80$ growth stage (Kumhálová et al., 2014). In contrast, Fig. 8 demonstrates that the upper plot areas can be adversely affected by drought. With lower precipitation in the upper part of the field in the early vegetation development stages, the relationship between NDVI and the yield frequency map (Table 5) was more prominent (2005: $\left.\mathrm{R}^{2}=0.398,2011: \mathrm{R}^{2}=0.494\right)$ than in the years with higher precipitation amounts $\left(2009: \mathrm{R}^{2}=0.243,2013: \mathrm{R}^{2}\right.$ $=0.190$ ). This trend was not apparent in the lower part of the field, even when the field was evaluated as a whole. It is emphasized by the information derived from Fig. 8. The relationship between NDVI and yield became more obvious with lower rainfall in the early stages of wheat growth in the upper part of the field $\left(\mathrm{R}^{2}=0.6-0.7\right)$ than in the years with higher rainfall $\left(\mathrm{R}^{2}=0.45-0.5\right)$. However, this trend was also not so obvious in the lower part of the field, nor when the field as a whole was evaluated.

From a practical point of view, the quality of wheat yield prediction provided by satellite NDVI imagery varies according to slope and weather conditions; and the prediction on sloped plots is therefore more precise in drier spring weather. This is explained by different Leaf Area Index values, the level of planting and the yields achieved during dry spring weather. When the evaluated area includes pixels is affected by water scarcity, there is a higher range of NDVI values and yields and the NDVI/yield relationship is altered. On the basis of our results, it may be concluded that the quality of the yield prediction on the more sloping areas is more dependent on precipitation than on the less sloping parts, and inversely proportional to it. Based on our results, it would also seem clear that a good knowledge of local conditions, such as topography, weather conditions, the course of precipitation, but also the crop variety can fundamentally affect satellite image interpretation. For example, when comparing the NDVI calculated from the satellite images shown in Fig. 5d of June 20, 2017, and the image taken from the available satellite data on June 16, 2013 in Fig. 3d, it is clear that these two images are very similar. There is a clear division of the experimental plot into two parts in both images. However, in the case of the 2013 picture, only one winter wheat variety (Brilliant) was grown on the plot, while in 2017 there were two different varieties of spring wheat (Seance in the upper part and Astrid in the lower one).

These results are in agreement with the study of Jelínek et al. (2019). The study demonstrated the uncertainty of yield predictions based on a yield frequency map and an NDVI frequency map which may have their limitations in agricultural praxis. While the best model for crop yield estimation was the yield frequency map for cereals which explains the yield variability from $44 \%$ on average for all of the selected years, so the best model for crop condition estimation seems to be the NDVI frequency map with a spatial resolution of $10 \mathrm{~m}$ according to the Sentinel 2 image from all of the years examined. This model explained the winter wheat crop structure from $96 \%$ and from $38 \%$ for all of the selected NDVI images. The models were also more significant for cereals and in drier and warmer years as well.

The model by Gili et al. (2017) and a comparison of the three methods of determining management zones established that the choice depends on the objectives of crop management and the main yield-limiting factors and agroecological conditions of the site. The interaction of these conditions and weather conditions may mask the differences in potential productivity between zones in a particular growing season. Moreover, the differences between the potential crop productivity zones can significantly influence the spectral response of the crops. These combined findings support the results of this study. In addition, 
Vincini et al. (2016) researched the sensitivity of leaf chlorophyll empirical estimators obtained at Sentinel 2 spectral resolution for different canopy structures. These authors determined that although the Chlorophyll Vegetation Index (CVI) is a potential tool for leaf chlorophyll estimation by Sentinel-2 data at $10 \mathrm{~m}$ spatial resolution, better results are obtained by differentiating between the indices according to leaf-angle distribution. However, this requires a preliminary knowledge of the crop canopy type which may be utilized in precision farming, but is not feasible for regional scale application.

A geometrical analysis of the canopy includes plant height, the number and distribution of leaves and also the leaf colour, size and angle, the plant canopy spectral response is primarily determined by water stress. Moreover, the relative contributions of physiognomy features the canopy spectral response which is dependent on the plant species and cultivars. These factors include plant and canopy geometry as well as leaf anatomy and physiology (Jackson and Ezra, 1985; Ehleringer and Forseth, 1980). It is therefore essential to have an adequate knowledge of the monitored canopy, this factor allowed the presented study to establish that crop spectral response is subject to overall cultivar features and their resistance to extreme weather conditions. In addition, although it is not always easy to estimate the growth stage from the spectral index values, the final crop yield may be estimated from the spectral index spatial distribution and trend. Similarly, while it may be difficult to choose the best available plant species and cultivar for a specific sloping plot, for example, a study of five wheat cultivars by Grohs et al. (2009) confirmed that the difference in cultivar reflectance values in the near infrared and red spectra does not sufficiently indicate their productive potential.

Cattani et al. (2017) then added results based on the In-Season Estimate of Yield model, where NDVI is normalized by degree-day accumulated from Feekes growth stages 2 and 8 . This appears to be a more consistent method of estimating grain yield, and in the context of climate change, this model may be more reliable and accurate for grain yield estimation in areas with higher temperatures and a lack of precipitation than solely calculating the spectral index, as occurred in this study. Moreover, the benefits of NDVI are controversial regarding the saturation effect and although it lacks sensitivity to alterations in LAI and biomass (Povh et al., 2008), it remains a proven spectral index with many research citations. The indices, however, can be simply calculated from Sentinel 2 and Landsat 8 images, and this will ensure historical temporal continuity. The replaceability of Sentinel 2 and Landsat 8 satellite images for agricultural purposes remains an open question. Although there is a significant overlap in the results produced by near infrared and red bands, the results derived from the images may differ. Mandanici and Bitelli (2016) compared the spectral differences between the Landsat 8
OLI and Sentinel 2 MSI sensors. They evaluated bands and selected indices, including NDVI. They calculated NDVI with B8A $(864 \mathrm{~nm})$ and B4 $(665 \mathrm{~nm})$. On the basis of their study it was reported that the correlation of the Pearson coefficient reached values ranging from 0.936 to 0.999 as measured in different geographical areas (especially semiarid areas, deserts or lakes), land covers and climatic conditions. We calculated the coefficient of determination between NDVI derived from Sentinel 2 (with bands B8 and $\mathrm{B} 4)$ and Landsat 8 images $\mathrm{R}^{2}=0.876(\mathrm{R}=0.938)$; and $\mathrm{R}^{2}=0.797(\mathrm{R}=0.893)$ for the bands $\mathrm{B} 8 \mathrm{~A}$ and $\mathrm{B} 4$. Our study showed that for agricultural purposes, in terms of our evaluation, it is more suitable to use the band B8 for NDVI calculations.

Finally, climate change is an important topic in the current literature (Rezaei et al., 2018). For example, Olesen et al. (2011) described its impact on crops, including winter wheat, and considered that drought and heat stress are increasing throughout Europe. In order to counteract the potentially harmful effects of climate change, farmers can adapt by changing the cultivation time, their variety and cultivar choice, adopt water saving techniques and irrigation and also crop-breeding techniques. Furthermore, these results provide a guide for central European agronomists in the selection of spring and winter wheat cultivars suitable for individual site-specific plots.

Our results present important knowledge concerning wheat cultivation and yields over a period of thirteen years, but since they are only based on one site, it would be beneficial to assess additional sites, especially those more affected by insufficient water. This research could also include monitoring selected cultivars resistant to extreme weather conditions.

\section{CONCLUSIONS}

1. The development of sensors carried on satellites is advancing rapidly. In the case of the American Landsat satellites, although the sensors gradually improved, the mission continued along the same lines. Therefore, the results of this mission are more comparable within a historical context. Nevertheless, the US Mission Landsat was then followed by a more modern European mission, Sentinel 2. In terms of agricultural use, it is an issue that the two bands offered by Sentinel 2 from the NIR range, B8 and B8A can be used for the calculation of the normalized difference vegetation index. Based on our results, we recommend the use of the Sentinel 2 B8 band to generate a better comparison with the Landsat mission results for agricultural purposes within a historical context.

2. In particular, the results confirmed that selected wheat cultivars reacted significantly to weather conditions and topography. A higher yield was recorded in the lower part of the experimental field, with the exception of 2005, this apparent anomaly was caused by the increased water supply in the later growth stages and management zones 
with different regimes of nitrogen fertilizer application. Similarly, the normalized difference vegetation index values were higher in the lower part of the field, regardless of the spectral response of the individual cultivars. Also, the quality of yield prediction in the upper, more steeply sloping part of the field depended more on precipitation and water supply than the lower portion with a lesser inclination, and this relationship was inversely proportional.

3. At this point, it should be noted that the effects of other yield-generating factors, such as the nutrient content of the soil, weather conditions or soil physical properties (especially compaction), etc., were beyond the scope of this research. These factors, together with a relatively large number of other variables that we could not control (crop rotation, etc.), of course, reduces the strength of the conclusions presented here to a slight extent.

4. With regard to long-term climate change, the field is divisible into site-specific zones based on the yield frequency map and canopy spectral response. In addition, the 2017 trial also contained drought-resistant cultivars which stabilized the yield. Experimental results confirmed that both the Landsat 8 OLI and Sentinel 2 MSI satellite systems are successful in crop yield prediction and crop stage estimation, and although only one vegetation season with spring wheat and two satellite sources were assessed, the satellite systems complemented each other. Moreover, they have the capacity to consolidate future data concerning topography and crop yield potential which will prove historically important. Furthermore, the coefficient of determination between the normalized difference vegetation index derived from Sentinel 2 and the Landsat 8 images scanned on the same day was 0.876 with the use of the B8 band for near infrared.

5. In conclusion, all information gained from this research, including the spectral properties of both crops and cultivars, is important for the management of agricultural plots and their response to climate change. Specialized knowledge of the chosen crops and varieties is crucial, and when the results from the Seance and Astrid cultivars in 2017 are compared to those of the Brilliant cultivar from 2013, it is evident that the amount of the water within the growth can significantly affect the growth's spectral characteristics. Therefore, a lack of specific cultivar knowledge and its emission spectra under different climatic conditions can prevent the identification of crop properties such as the accurate estimation of both crop yield and leaf nitrogen content through the spectral reflection of the vegetation.

Conflict of interest: The authors do not declare conflict of interest.

\section{REFERENCES}

Agrometeorological station, 2018. Crop Research Institute Prague. https://www.vurv.cz/meteo/meteograf.htm

Andarzian B., Bakhshandeh A.M., Bannayan M., Emam Y., Fathib G., and Alami Saeedb K., 2008. WheatPot: A sim- ple model for spring wheat yield potential using monthly weather data. Biosys. Eng., 99, 487-495. doi: 10.1016/j. biosystemseng.2007.12.008

Benedetti R. and Rossini P., 1993. On the use of NDVI profiles as a tool for agricultural statistics. The case study of wheat yield estimate and forecast in Emilia Romagna. Remote Sensing Environ., 45, 311-326. doi: 10.1016/0034-4257(93)90113-C.

Cattani C.E.V., Garcia M.R., Mercante E., Johann J.A., Correa M.M., and Oldoni L.V., 2017. Spectral-temporal characterization of wheat cultivars through NDVI obtained by terrestrial sensors. Revista Brasileira de Engenharia Agrícola e Ambiental, 21, 769-773

Chemura A., Mutanga O., Odindi J., and Kutywayo D., 2018. Mapping spatial variability of foliar nitrogen in coffee (Coffea arabica L.) plantations with multispectral Sentinel-2 MSI data. ISPRS. J. Photogrammetry Remote Sensing, 138, 1-11. doi: 10.1016/j.isprsjprs.2018.02.004

Clevers J.G.P.W., Kooistra L., and van den Brande M.M.M, 2017. Using Sentinel-2 data for retrieving LAI and leaf canopy chlorophyll content of a potato crop. Remote Sensing, 9: 405. doi: $10.3390 /$ rs 9050405

Copernicus Open Access Hub by ESA, 2018. https://scihub. copernicus.eu

Doerge T.A., 1999. Yield map interpretation. J. Production Agric., 12, 54-61. doi: 10.2134/jpa1999.0054

Domínguez J.A., Kumhálová J., and Novák P., 2015. Winter oilseed rape and winter wheat growth prediction using remote sensing methods. Plant Soil Environ., 61, 410-416. doi: 10.17221/412/2015-PSE

Domínguez J.A., Kumhálová J., and Novák P., 2017. Assessment of the relationship between spectral indices from satellite remote sensing and winter oilseed rape yield. Agronomy Res., 15, 55-68.

Du M. and Noguchi N., 2017. Monitoring of wheat growth status and mapping of wheat yield's within-field spatial variations using color images acquired from UAV-camera system. Remote Sensing, 9, 289. doi: 10.3390/rs9030289

Ehleringer J., and Forseth I., 1980. Solar tracking by plants. Science, 210, 1094. doi: 10.1126/science.210.4474.1094

Evans L.T., 1993. Crop Evolution, Adaptation and Yield. Cambridge University Press, Cambridge, Great Britain: 500.

Flynn K.C., Frazier A.E., and Admas S., 2020. Performance of chlorophyll prediction indices for Eragrostis tef at Sentinel-2 MSI and Landsat-8 OLI spectral resolutions. Precision Agriculture, doi: 10.1007/s11119-020-09708-4

Gili A., Álvarez C., Bagnato R., and Noellemeyer E., 2017. Comparison of three methods for delineating management zones for site-specific crop management. Computers and Electronics Agric., 139, 213-223. doi: 10.1016/j.compag.2017.05.022

Goméz C., White J.C., and Wulder M.A., 2016. Optical remotely sensed time series data for land cover classification: A review. ISPRS J. Photogrammetry Remote Sensing, 116, 55-72. doi: 10.1016/j.isprsjprs.2016.03.008

Grassini P., van Bussel L.G.J., van Wart J., Wolf J., Claessens L., Yang H., Boogaard H., de Groot H., van Ittersum M.K., and Cassman K.G., 2015. How good is good enough? Data 
requirements for reliable crop yield simulations and yieldgap analysis. Field Crops Res., 117, 49-63. doi: 10.1016/j. fcr.2015.03.004

Grohs D.S., Bredemeier C., Mundstock C.M., and Poletto N., 2009. Modelo para estimativa do potencial produtivo em trigo e cevada por meio do sensor GreenSeeker. Engenharia Agrícola, 29, 101-112. doi: 10.1590/S0100-69162009000100011

Guilpart N., Grassini P., Sadras V.O., Timsina J., and Cassman K.G., 2017. Estimating yield gaps at the cropping system level. Field Crops Res., 206, 21-32. doi: 10.1016/j.fcr.2017.02.008

Heumann B.W., Seaquist J.W., Eklundh L., and Jönsson P., 2007. AVHRR derived phenological change in the Sahel and Soudan, Africa, 1982-2005. Remote Sensing Environ., 108: 385-392. doi: 10.1016/j.rse.2006.11.025

Jackson R.D. and Ezra C.E., 1985. Spectral response of cotton to suddenly induced water stress. Int. J. Remote Sensing, 6, 177-185. doi: 10.1080/01431168508948433

Jamali S., Jönsson P., Eklundh L., Ardö J., and Seaquist J., 2015. Detecting changes in vegetation trends using time series segmentation. Remote Sensing Environ., 156, 182-195. doi: 10.1016/j.rse.2014.09.010

Jelínek Z., Starý K., and Kumhálová J., 2019. Assessment of production zones modelling accuracy based on satellite imaging and yield measurement of selected agriculture plot. Agronomy Res., 17(2), 447-455. doi: 10.15159/AR.19.102

Jin Z., Azzari G., Burke M., Aston S., and Lobell D.B., 2017. Mapping smallholder yield heterogeneity at multiple scales in Eastern Africa. Remote Sensing, 9, 931. doi: 10.3390/ rs 9090931

Julien Y., Sobrino J.A., and Jiménez-Muñoz J.C., 2011. Land use classification from multitemporal Landsat imagery using the yearly land cover dynamics (YLCD) method. Int. J. Applied Earth Observation and Geoinformation, 13, 711720. doi: 10.1016/j.jag.2011.05.008

Kumhálová J., Kumhála F., Kroulík M., and Matějková Š., 2011. The impact of topography on soil properties and yield and the effects of weather conditions. Precision Agric., 12, 813830. doi: 10.1007/s11119-011-9221-x

Kumhálová J. and Matějková Š., 2017. Yield variability prediction by the remote sensing sensors with different spatial resolution. Int. Agrophys., 31, 195-202. doi: 10.1515/ intag-2016-0046

Kumhálová J., Matějková Š., Fifernová M., Lipavský J., and Kumhála F., 2008. Topography impact on nutrition content in soil and yield. Plant, Soil Environ., 54, 255-261. doi: 10.17221/257-PSE

Kumhálová J. and Moudrý V., 2014. Topographical characteristics for precision agriculture in conditions of the Czech Republic. Appl. Geography, 50, 90-98. doi: 10.1016/j. apgeog.2014.02.012

Kumhálová J., Zemek F., Novák P., Brovkina O., and Mayerová M., 2014. Use of Landsat images for yield evaluation within a small plot. Plant Soil Environ., 60, 501-506. doi: 10.17221/515/2014-PSE

Landsat Science, 2020. https://landsat.gsfc.nasa.gov/landsat-8/ landsat-8-overview/

Long D.S. and McCallum J.D., 2014. On-combine, multi-sensor data collection for post-harvest assessment of environmental stress in wheat. Precision Agric., 16, 492-504. doi: 10.5307/JBE.2016.41.4.408

Mandanici E., and Bitelli G., 2016. Preliminary comparison of Sentinel 2 and Landsat 8 imagery for a combined use. Remote Sensing, 8, 1014. doi: 10.3390/rs8121014

Maphanyane J.G., Mapeo R.B.M., and Akinola M.O., 2018. Handbook of research on geospatial science and technologies . IGI Global, Hershey, PA, USA: 457.

Matějková Š., Kumhálová J., and Lipavský F., 2010. Evaluation of crop yield under different nitrogen doses of mineral fertilization. Plant, Soil Environ., 56, 163-167. doi: 10.17221/196/2009-PSE.

Mueller N.D., Gerber J.S., Johnston M., and Ray D.K., Ramankutty N., and Foley J.A., 2013. Closing yield gaps through nutrient and water management. Nature, 490, 254257. doi: $10.1038 /$ nature 11420

Nearing G.S., Crow W.T., Thorp K.R., and Moran M.S., Reichle R.H., and Gupta H.V., 2010. Assimilating remote sensing observations of leaf area index and soil moisture for wheat yield estimates: An observing system simulation experi- ment. Water Res. Res., 48, W05525. doi: 10.1029/2011WR011420

Olesen J.E., Trnka M., Kersebaum K.C., Skjelvåg A.O., Seguin B., Peltonen-Sainio P., Rossi F., Kozyra J., and Micale F., 2011. Impacts and adaption of European crop production systems to climate change. Eur. J. Agron., 34, 96-112. doi: 10.1016/j.eja.2010.11.003

Povh F.P., Molin J.P., Gimenez L.M., Pauletti V., Molin R., and Salvi J.V., 2008. Properties of NDVI obtained by an active optical sensor in cereals. Pesquisa Agropecuária Brasileira, 43, 1075-1083. doi: 10.1590/S0100-204X2008000800018

Rezaei E.E., Siebert S., Hüging H., and Ewert F., 2018. Climate change effect on wheat phenology depends on cultivar change. Scientific Reports, 8, 4891. doi: 10.1038/s41598-018-23101-2

Schmidt F. and Persson A., 2003. Comparison of DEM data capture and topographic wetness indices. Precision Agric., 4, 179-192. doi: 10.1023/A:1024509322709

Scudiero E., Corwin D.L., Wienhold B.J., Bosley B., Shanahan J.F., and Johnson C.K., 2016. Downscaling Landsat 7 canopy reflectance employing a multi-soil sensor platform. Precision Agric., 17, 53-73. doi: 10.1007/s11119-015-9406-9

Scudiero E., Skaggs T.H., and Corwin D.L.C., 2014. Regional scale soil salinity evaluation using Landsat 7, western San Joaquin Valley, California, USA. Geoderma Regional, 2-3, 82-90. doi: doi.org/10.1016/j.geodrs.2014.10.004

Sentinel Online, Available, 2020. https://sentinels.copernicus.eu/ web/sentinel/missions/ sentinel-2

Shanahan J.F., Schepers J.S., Francis D.D., Varvel G.E., Wilhelm W.W., and Tringe J.M., 2001. Use of remotesensing imagery to estimate corn grain yield. Agronomy J., 93, 583-589. doi: 10.2134/agronj2001.933583x

Sørensen R., Zinko U., and Seibert J., 2006. On the calculation of the topographic wetness index: Evaluation of different methods based on field observations. Hydrology Earth System Sci., 10, 101-112. doi: 10.5194/hess-10-101-2006.

Spring wheat cultivars Seance, Selgen, 2018. http://selgen.cz/ obiloviny/psenice-jarni-2/seance 
Šíp V., Chrpová J., Žofajová A., and Milec Z., 2011. Evidence of selective changes in winter wheat in middle-European environments reflected by allelic diversity at loci affecting plant height and photoperiodic response. J. Agric. Sci., 149, 313-326. doi: 10.1017/S002185961000078X

Thorp K.R., Hunsaker D.J., and French A.N., 2001. Assimilating leaf area index estimates from remote sensing into the simulations of a cropping systems model. Trans. ASABE, 53, 251-262. doi: 10.3390/w10101367

US Geological Survey (USGS), 2018. http://earthexplorer.usgs. gov

Van Leeuwen W.J.D. and Huete A.R., 1996. Effects of standing litter on the biophysical interpretation of plant canopies with spectral indices. Remote Sensing Environ., 55, 123138. doi: 10.1016/0034-4257(95)00198-0

Vincini M., Calegari F., and Casa R., 2016. Sensitivity of leaf chlorophyll empirical estimators obtained at Sentinel-2 spectral resolution for different canopy structures. Precision Agric., 17, 313-331. doi: 10.1007/s11119-015-9424-7

Viña A., Gitelson A.A., Nguy-Robertson A.L., and Peng Y., 2011.
Comparison of different vegetation indices for the remote assessment of green leaf area index of crops. Remote Sensing Environ., 115, 3468-3478. doi: 10.1016/j.rse.2011.08.010

Wheeler T.R., Hong T.D., Ellis R.H., Batts G.R., Morison J.I.L., and Hadley P., 1996. The duration and rate of grain growth, and harvest index, of wheat (Triticum aestivum L.) in response to temperature and $\mathrm{CO}_{2}$. J. Experimental Botany, 47, 623-630. doi: $10.1093 / \mathrm{jxb} / 47.5 .623$

Winter wheat cultivars Baletka and Brilliant, 2018. http://eagri.cz/ public/web/file/ 404470/Psenice_ozima_2015.pdf

Winter wheat cultivar Ebi, 2018. http://eagri.cz/public/web/ file/112944/SDO_ListovkaPO.pdf

Wu Q., Wang C., Fang J.J., and Ji J.W., 2016. Field monitoring of wheat seedling stage with hyperspectral imaging. Int. J. Agric. Biological Eng., 9, 143-148. doi: $10.3965 /$ j.ijabe.20160905.1707

Zhang F., Wu B., and Luo Z., 2004. Winter wheat yield predicting for America using remote sensing data. J. Remote Sensing, 8, 611-617. doi: 10.1371/journal.pone.0070816 